\title{
Propostas de produção de textos em material didático e a noção de "escrita como trabalho"
}

DOI: http://dx.doi.org/10.21165/el.v49i3.2695

\section{Marina Célia Mendonça'}

\section{Resumo}

Este trabalho se insere no contexto das pesquisas das ciências da linguagem sobre a produção textual como processo e sua inserção em atividades didático-pedagógicas. Considerando essa problemática, o objetivo é colocar em foco escritos de pesquisadores brasileiros, nas áreas da Linguística e da Linguística Aplicada, discutindo sua atualização no discurso sobre a produção textual em material didático - é enfocada, especificamente, a noção de "escrita como trabalho", atualizada por uma coleção didática direcionada ao Ensino Médio intitulada Veredas da Palavra. O suporte teórico-metodológico da pesquisa são os estudos bakhtinianos do discurso. O procedimento metodológico central é o cotejamento de textos, comparando discursos produzidos em esferas de atividade diferentes. O pressuposto teórico de que se parte é o de que, ao migrar de uma esfera de atividade para outra, o discurso sofre modificações decorrentes de novas relações discursivas estabelecidas na nova esfera e de valores que são predominantes nela.

Palavras-chave: estudos bakhtinianos; material didático; produção de texto.

1 Universidade Estadual Paulista "Júlio de Mesquita Filho", Araraquara, São Paulo, Brasil; marina.mendonca@unesp.br; http://orcid.org/0000-0002-5712-2346 


\title{
Textbook writing proposals and the notion of "writing is a work"
}

\begin{abstract}
This work is related to the context of language research on "writing as a process" and its relation to didactic and pedagogical activities. Considering this context, the objective of this work is to discuss how Brazilian works in the Linguistics and Applied Linguistics area dialogue with the discourse about writing that appears in Brazilian textbooks. Specifically, the goal is to analyze how the notion that writing is a work appears in a high school textbook entitled Veredas da Palavra. The theoretical support of the research is the Bakhtinian discourse studies. The main methodological procedure is the comparison of texts, comparing discourses produced in different spheres of activity. The theoretical assumption on which this paper is based is that discourse changes when it goes from one sphere of activity to another. These modifications are the result of new discursive relations established in the new sphere and of values that are predominant in it.
\end{abstract}

Keywords: Bakhtinian studies; textbook; writing.

\section{Introdução}

Este artigo se insere no contexto de pesquisas das ciências da linguagem sobre a produção textual escrita e sua inserção em atividades didático-pedagógicas e em materiais didáticos. $\mathrm{O}$ trabalho é parte de resultados de pesquisa desenvolvida no interior de projeto de pós-doutorado na Universidade Estadual de Campinas (SP) ${ }^{2}$, que teve por objetivo investigar "como o discurso das ciências da linguagem sobre a relação da subjetividade com o texto/discurso é atualizado em coleções didáticas direcionadas ao Ensino Médio e aprovadas pelo Programa Nacional do Livro Didático (PNLD)".

Considerando essa problemática, o objetivo aqui é colocar em foco escritos de autores brasileiros sobre a reescrita e/ou refacção e/ou planejamento textual, discutindo sua atualização no discurso sobre a produção textual em uma coleção didática direcionada ao Ensino Médio intitulada Veredas da Palavra (ALVES; MARTIN, 2016), em versão direcionada ao professor. Especificamente, são analisadas propostas de produção textual escrita dessa coleção, bem como orientações dadas aos docentes para encaminhamento de atividades.

Partimos de resultados de pesquisa anterior (MENDONÇA, 2019), em que analisamos a atualização de estudos sobre aquisição da escrita em documentos oficiais brasileiros. Esses resultados são apresentados resumidamente, destacando-se o que interessa

20 projeto foi desenvolvido de agosto de 2018 a julho de 2019 no Instituto de Estudos da Linguagem, da UNICAMP, no Programa de Pós-doutorado, sob supervisão de Sírio Possenti. 
especificamente a este artigo, na seção a seguir, que antecede a análise de propostas de produção textual escrita da coleção didática selecionada.

O suporte teórico-metodológico da pesquisa são estudos bakhtinianos do discurso, em especial as noções de diálogo, esfera de atividade, tema e significação. O procedimento metodológico privilegiado é o cotejamento de textos (GERALDI, 2012), em que se apresentam ao enunciado, no processo de interpretação, novos contextos. Bakhtin (2000, p. 404), quando reflete sobre a especificidade da pesquisa nas Ciências Humanas, defende que "A compreensão é o cotejo de um texto com os outros textos. [...] Compreender é cotejar com outros textos e pensar num contexto novo (no meu contexto, no contexto contemporâneo, no contexto futuro)". Seguindo essa proposta, temos desenvolvido esse procedimento em nossos últimos trabalhos (ver Mendonça, 2013, 2015, 2016, 2018, 2019); neste artigo, para lançar luz sobre a interpretação de uma coleção didática, são colocados em diálogo discursos produzidos em diferentes esferas da comunicação: na esfera científica (Ciências da Linguagem) e na didático-pedagógica (documentos que definem diretrizes para a esfera escolar brasileira e uma coletânea didática direcionada ao Ensino Médio).

Grillo e Glushkova (2016), no desenvolvimento de uma metodologia de análise comparativa de textos de culturas diferentes que tenha relação com os estudos de Bakhtin e o Círculo, chamam atenção para a presença da comparação como base para a metodologia na obra bakhtiniana. Já em um de seus primeiros ensaios, "O autor e a personagem na atividade estética", Bakhtin (2000) coloca em relação obras e autores de culturas variadas, bem como "esferas de uma mesma cultura (música, dança, literatura, religião etc.)" (GRILLO; GLUSHKOVA, 2016, p. 71) Posteriormente, em ensaio publicado numa revista russa no início dos anos 1970, Bakhtin (2000) defende que se estude literatura tendo em vista a cultura da sociedade em que ela está inserida, um projeto que, como destacam Grillo e Glushkova (2016), exige que se coloque a esfera literária em relação com outras esferas da cultura.

Tendo em vista essas considerações de Bakhtin e seus comentadores, utilizamos aqui a noção de diálogo para entender as relações entre o discurso da esfera científica sobre reescrita e/ou refacção e/ou planejamento e o discurso que se produz na esfera didáticopedagógica, nos gêneros discursivos documento oficial e livro didático. Essa noção atravessa toda a obra de Bakhtin e o Círculo e é base para se entender o enunciado como "um elo na cadeia da comunicação verbal" que "não pode ser separado dos elos anteriores que o determinam, por fora e por dentro, e provocam nele reações-respostas imediatas e uma ressonância dialógica" (BAKHTIN, 2000, p. 320) Essas reações-respostas, tal como afırma o autor neste ensaio (em que toma por objeto os gêneros do discurso), dão-se no interior de uma determinada esfera da comunicação verbal. 
A noção de esfera, que aparece nas traduções de textos de Bakhtin e o Círculo também como campo ou domínio - ver a respeito Grillo (2006) e Grillo e Glushkova (2016) -, é recorrente na obra e é importante para se pensar não somente as semelhanças nos gêneros discursivos de uma mesma esfera e nos valores que os orientam, mas também as diferenças entre discursos produzidos em esferas diferentes. Isso porque Bakhtin (2000) concebe as esferas como domínios que possuem, entre outros aspectos, diferentes formas de tratamento do tema de um enunciado. Dessa forma, defendemos aqui que a noção é importante para análises em que se produz cotejo de textos, seja no interior de uma mesma esfera seja entre diferentes campos. Uma reflexão mais aprofundada dessa questão encontra-se em Mendonça (2019).

Dessa maneira, quando um enunciado se apropria de outro (em forma de comentário, citação etc.), seu sentido sofre influências do novo contexto em que se deu a apropriação, do novo acontecimento desse enunciado. Volóchinov (2017) apresenta uma discussão sobre a unidade e singularidade do enunciado tendo em vista o sentido produzido nesse novo contexto, a partir do que ele chama de significação e tema. A significação é entendida como a base estável sobre a qual se sustenta o sentido, e o tema é o lugar do sentido novo, singular e irrepetível, que se produz quando da atualização do enunciado em outros contextos. É importante dizer que essa concepção de atualização como singularidade, antes de constituir um argumento contra a estabilidade do enunciado, é que explica a possibilidade de sua estabilidade relativa, pois é com base na significação que se produz o novo sentido. Também é relevante destacar que a ideia de singularidade do enunciado, no momento de um novo "aparecimento", tanto se aplica a cronotopos próximos quanto a distantes - em outra esfera, em outro tempo e até, conforme Bakhtin, naquilo que ele chama de grande temporalidade:

Não há uma palavra que seja a primeira ou a última, e não há limites para o contexto dialógico (este se perde num passado ilimitado e num futuro ilimitado). Mesmo os sentidos passados, aqueles que nasceram do diálogo com os séculos passados, nunca estão estabilizados (encerrados, acabados de uma vez por todas). Sempre se modificarão (renovando-se) no desenrolar do diálogo subsequente, futuro. Em cada um dos pontos do diálogo que se desenrola, existe uma multiplicidade inumerável, ilimitada de sentidos esquecidos, porém, num determinado ponto, no desenrolar do diálogo, ao sabor de sua evolução, eles serão rememorados e renascerão numa forma renovada (num contexto novo). [...] Todo sentido festejará um dia seu renascimento. O problema da grande temporalidade. (BAKHTIN, 2000, p. 414).

Neste artigo, nosso interesse é cotejar discursos sobre a noção de "escrita como trabalho", que remete às práticas de reescrita e/ou refacção e/ou planejamento, em dois "contextos" diferentes: esfera científica e esfera didático-pedagógica, de forma a entender o sentido que se produz num novo tema do discurso. Na seção que se segue, retomamos discussão 
desenvolvida em Mendonça $(2013,2015,2019)$, em que cotejamos o discurso científico e o atualizado em documentos oficiais brasileiros, e, na última seção, analisamos propostas de produção textual escrita do material didático selecionado para corpus desta pesquisa.

\section{A "escrita como trabalho": o discurso das ciências da linguagem e dos documentos oficiais}

A "escrita como trabalho" tem sido objeto de pesquisa em contexto científico relacionado à Aquisição da Escrita, em Linguística e Linguística Aplicada, em que se busca entender a escrita como "processo" e não somente como "produto". Há uma grande quantidade de pesquisas que têm sido desenvolvidas nessa subárea dos estudos da linguagem, especialmente pelos enfoques que se dão nessas últimas décadas aos letramentos e multiletramentos. Aqui, faço um recorte dessas pesquisas, dando centralidade aos trabalhos desenvolvidos por Fiad e Mayrink-Sabinson (1991) e Abaurre, Fiad, MayrinkSabinson (1997) e outros que dialogam mais diretamente com eles.

Nessas publicações, as autoras propõem que se tome a escrita como trabalho do sujeito. Assumem como ponto de partida para o projeto de investigação proposto a concepção de Possenti sobre trabalho do sujeito e estilo. Conforme Possenti (1993), há estilo se e quando há marca de trabalho do sujeito sobre o interdiscurso - sua reflexão localiza-se no contexto do quadro teórico da Análise do Discurso francesa e, ao ser atualizada nessas pesquisas em Aquisição da Escrita, é objeto de deslocamentos que não discutirei neste artigo, pelas limitações do recorte e objetivo em pauta.

A noção de linguagem com a qual se opera nessas pesquisas é interacionista, conforme se propõe a seguir:

[...] assumimos uma concepção sócio-histórica de linguagem, vista como lugar de interação humana, de interlocução. Tomada como atividade, como trabalho, a linguagem, ao mesmo tempo que constitui os pólos da subjetividade e da alteridade, é também constantemente modificada pelo sujeito, que sobre ela atua. (ABAURRE; FIAD; MAYRINK-SABINSON, 1997, p. 302).

As autoras destacam etapas no processo da escrita: o planejamento; a revisão efetuada pelo próprio escrevente quando da leitura de seu texto; a revisão feita após interferência de um outro (professor, mãe, colega...). Destacam que as formas de interação ocorridas no processo da escrita podem interferir significativamente, por exemplo, no resultado da revisão e nas formas de relação subjetiva do escrevente com sua própria escrita e com seu interlocutor; entendem ainda que a produção escrita é uma atividade em que emerge a singularidade dos sujeitos: "A escrita é, assim, um espaço a mais, importantíssimo, de manifestação da singularidade dos sujeitos." (ABAURRE; FIAD; MAYRINK-SABINSON, 1997, p. 23). 
As pesquisas mostram que as alterações realizadas nos textos pelos escreventes são respostas a intervenções do leitor/interlocutor e, inclusive, não são superficiais: têm por objetivo tornar o texto mais adequado tendo em vista o interlocutor. Mostram que episódios de refacção e/ou revisão textual podem ser entendidos como indícios que "dão visibilidade ao trabalho do sujeito em seu processo de constituição de uma relação particular com a linguagem e com sua representação escrita." (ABAURRE; FIAD; MAYRINK-SABINSON, 1997, p. 8). Segundo as autoras, é preciso considerar tanto o papel do interlocutor quanto o da escola nas alterações que o escrevente faz em seu texto.

As autoras apresentam proposta metodológica de prática de escrita na escola: a aquisição da escrita se daria pela aprendizagem do trabalho de reescritas, que, como veremos, será incorporado por documentos oficiais direcionados à educação básica. Destacamos, enfim, que a pesquisa em pauta coloca em evidência o projeto de dizer do escrevente, sendo esse projeto central nas atividades de revisão e/ou reescrita - o escrevente, ao realizar um "trabalho" sobre o seu próprio texto, constitui-se como autor, na relação com o interlocutor.

É importante destacar também proposta de ensino/aprendizagem que envolve reescrita de textos feita por Geraldi (1984), em O texto na sala de aula, em que o autor propõe que a disciplina Língua Portuguesa se organize em torno do uso do texto em atividades de leitura/compreensão oral, escrita/produção oral, e análise linguística - esta envolveria situações de discussão e reescrita de textos de alunos, em que atividades metalinguísticas e epilinguísticas seriam desenvolvidas, no trabalho com e sobre a linguagem.

A partir dos primeiros resultados desses estudos e propostas, outras pesquisas ainda na década de 1990 tomam por tema a reescrita em contexto escolar. Grillo (1996), em dissertação de mestrado orientada por Fiad e defendida em 1995, confirma os estudos citados, considerando principalmente as interferências feitas pelo professor nos textos de estudantes: a etapa do planejamento é importante para a qualidade do texto final e, se feita com a participação do educador, obtém-se melhor resultado; se o professor apresenta soluções para os problemas destacados em sua leitura do texto, há mais chance de melhora da produção escrita - ou seja, a qualidade da interferência influencia na qualidade do texto final. Jesus (1996), em dissertação orientada por Geraldi também em 1995, em estudo de intervenções de docentes na escola básica à época, mostra que há uma compreensão da tarefa de revisão de textos na escola em que se enfocam problemas na superfície textual, promovendo uma "higienização", sem se atentar para aspectos macrotextuais e para atividades que possam estimular a autoria e o processo de interação com o interlocutor. Citamos também o trabalho de Ruiz (1999), resultado de tese de doutorado defendida em 1998 e que ganha publicação em livro, sobre a correção de textos escritos na escola básica, em que a autora discute diferentes modos de intervenção dos professores quando das atividades de reescrita e sua interferência na produção escrita dos escreventes. 
Assim, a proposta de ensino/aprendizagem de escrita a partir de reescritas, com base em operações como substituição, apagamento, deslocamento e acréscimo, tal como proposto por Fiad e Mayrink-Sabinson (1991), foi objeto de debates/adesões antes mesmo da publicação dos Parâmetros Curriculares Nacionais, que, como veremos adiante, incorporam-na. Chamo atenção para texto de Geraldi publicado nos Anais de um Seminário do GEL na década de 1990, resultado de debates empreendidos em grupo de trabalho sobre o tema no evento, em que o autor comenta a proposta: "Estes quatro tipos de meta-operações estão a indicar um caminho metodológico possível para a produção de textos na escola, desde que o professor se torne leitor e co-autor dos textos de seus alunos." (GERALDI, 1994, p. 380).

Os Parâmetros Curriculares Nacionais direcionados ao Ensino Fundamental I e Ensino Fundamental II, publicados respectivamente em 1997 e 1998, incorporam a proposta de reescrita e planejamento em práticas de escrita escolar, conforme discutimos em Mendonça (2019). O documento enfatiza a relação do escrevente com o processo de produção textual, o que se pode considerar um avanço em relação a concepções anteriores, em que o texto escolar era um produto deslocado de sua situação de interação discursiva. Entretanto, os documentos supõem na atividade um movimento de "monitoramento" das atividades de escrita, dando um novo tema aos estudos de Fiad, Abaurre e Mayrink-Sabinson (1991), que buscam nas metaoperações de substituição, apagamento, deslocamento e acréscimo somente indícios da presença do sujeito no texto e do diálogo com o interlocutor; pela natureza da pesquisa - indiciária, com base no Paradigma Indiciário proposto por C. Ginzburg (1999) -, chegam a resultados que permitem perceber somente pequenos movimentos singulares que se mostram nas práticas de escrita. Veja-se trecho do documento direcionado ao EF I:

[...] a revisão do texto assume um papel fundamental na prática de produção. É preciso ser sistematicamente ensinada, de modo que, cada vez mais, assuma sua real função: monitorar todo o processo de produção textual desde o planejamento, de tal maneira que o escritor possa coordenar eficientemente os papéis de produtor, leitor e avaliador do seu próprio texto. Isso significa deslocar a ênfase da intervenção, no produto final, para o processo de produção, ou seja, revisar, desde o planejamento, ao longo de todo o processo: antes, durante e depois. (BRASIL, 1997, p. 51, grifo nosso).

Essa caracterização de um sujeito ativo nas atividades de escrita, agente do processo de significação e estruturação do seu texto, também aparece em outros volumes dos PCN. No caso dos volumes dirigidos ao Ensino Médio (BRASIL, 2000a, 2000b), lista-se uma competência que se espera desenvolver no educando, a qual inclui ser protagonista no processo de produção/recepção: esse protagonismo exigiria do escrevente que fizesse escolhas adequadas a seus interlocutores e ao contexto de uso dos gêneros. 
O discurso sobre a necessidade de planejamento e revisão da escrita também é atualizado em outro documento, duas décadas depois dos PCN, o PNLD 2018: língua portuguesa guia de livros didáticos - Ensino Médio, conforme também apontado em Mendonça (2019). Nos critérios para avaliação das coleções e nas resenhas das coleções aprovadas pelo programa, é atualizado o discurso sobre as etapas da produção textual, contudo não aparece no documento a expressão escrita como trabalho, talvez porque, na esfera didático-pedagógica, esse discurso entre em conflito com o que chamamos de ideologia da inspiração, presente no senso comum sobre a escrita.

As etapas da produção textual, conforme o PNLD 2018: língua portuguesa - guia de livros didáticos - Ensino Médio, aparecem como parte da metodologia esperada no ensino/ aprendizagem da escrita na esfera escolar, mas a relação do sujeito com o texto produzido não aparece explicitada nesse discurso sobre a escrita escolar. Vejamos um fragmento do documento:

Quanto ao eixo de Produção Textual, foram considerados os aspectos voltados para o aprimoramento das práticas de escrita dos estudantes, entre os quais, a atenção aos diferentes letramentos; aos contextos de produção da escrita; aos processos de planejamento, escrita e reescrita, em função da situação comunicativa e dos objetivos do texto [...]. (BRASIL, 2017, p. 13).

Considerando esses aspectos discutidos, as questões que motivaram esta pesquisa que toma por objeto material didático aprovado no PNLD foram: 1) Em que medida as atividades de reescrita estão integradas às de análise linguística? - esta integração encontra-se em proposta de Geraldi (1984), já citada aqui; 2) Em que medida a presença do professor é tomada como importante nesse processo de escrita em contexto escolar? - como vimos nos estudos citados, a presença do professor seria fundamental no processo de desenvolvimento da escrita na metodologia que assume o planejamento e a reescrita como etapas importantes para o aprendizado da escrita.

\section{A escrita como processo em uma coleção didática direcionada ao Ensino Médio}

A coleção didática Veredas da Palavra, que é o corpus deste trabalho, dá espaço considerável para as atividades de revisão textual. Nesse material, aprovado pelo PNLD 2018, cada capítulo dedicado à produção textual contém um roteiro de avaliação da produção antes de finalizá-la - essa avaliação, na forma de apresentação das propostas de escrita, constitui uma "rotina" bastante positiva de autoavaliação dos textos e de avaliação pelos colegas antes de ser entregue ao professor; este aspecto poderia ter sido valorizado pela equipe do PNLD, apesar de não aparecer citado na resenha da obra feita pelo guia. Transcrevemos a seguir o que a resenha traz sobre a produção textual escrita dessa coleção: 
A obra procura geralmente situar as propostas de escrita em seu contexto de uso social, contextualizando o gênero do texto escrito a ser produzido. Diferentes letramentos e gêneros são trabalhados, envolvendo a produção de textos, como poema, conto, microconto, cena teatral, reportagem, notícia, resenha, ensaio, currículo, relatório de pesquisa e dissertação escolar.

Se, na apresentação do gênero, são mencionados aspectos da situação de interação e sua função social, na proposição da atividade de escrita, contudo, os elementos da situação de interação, tais como, autoria, interlocutor previsto e função social do gênero são pouco considerados. O interlocutor efetivo dos textos produzidos poderia ter um espectro mais amplo, uma vez que a coleção enfoca, prioritariamente, os próprios estudantes como interlocutores. A abordagem fica a dever também no que tange ao trabalho com recursos e práticas multimodais como itens constituintes das práticas de produção textual. [...]. (BRASIL, 2017, p. 50).

Já na apresentação da coleção didática, as autoras dão destaque para o "Roteiro de Avaliação", dirigindo sua atividade persuasiva para dois destinatários imediatos, o professor e o avaliador do PNLD, que tem como critério de avaliação a noção da escrita como processo, como vimos na seção anterior. Assim, apesar de a seção dedicada à produção textual, no livro, se intitular "Produção do gênero", o material didático coloca em destaque, na apresentação da obra, o título "Roteiro de avaliação". Nessa apresentação, no texto que se pretende resumir as atividades de produção de textos presentes no volume - veja-se trecho (01) a seguir -, as autoras dialogam com os critérios utilizados pelo PNLD na avaliação dos livros: necessidade de que se trabalhe com a diversidade de gêneros textuais e em diferentes modalidades, que se trabalhe com a contextualização dessas produções, com a noção de escrita como processo. Assim, após o título "Roteiro de avaliação", nesta seção de apresentação da obra aparece o seguinte texto:

Em todos os capítulos de Produção de texto são apresentadas orientações específicas para a produção e socialização dos diversos textos orais e escritos propostos, além de um Roteiro de avaliação desses textos. Dessa forma, as produções escrita e oral não se limitam a uma execução simplificada e repetitiva. (ALVES; MARTIN, 2016).

No entanto, apesar desse aspecto positivo do material didático em pauta (apresentar sistematicamente atividades de autoavaliação e avaliação coletiva de textos escritos pelos estudantes), as atividades de análise linguística estão desvinculadas das de produção textual. Assim, a proposta de Geraldi (1984), de que as práticas de análise linguística, na escola, se deem a partir da produção dos alunos, de forma a permitir uma reflexão sobre aspectos pertinentes às dificuldades encontradas pelos sujeitos no processo de ensino/ aprendizagem, não se realiza nesse material didático - a análise linguística poderia se dar, na proposta de Geraldi, quando das atividades de revisão e correção textual, estas podendo servir como um espaço de discussão de questões linguísticas ou discursivas 
que fossem relevantes na produção dos sujeitos. Dessa forma, os três volumes da coleção se dividem em unidades, constituídas por capítulos, sendo o último capítulo de cada unidade dedicado à produção de textos, que se apresenta como um "fechamento" de cada unidade. Então, o movimento proposto, no trabalho com a linguagem, é sempre no sentido da leitura para a escrita, sendo que a análise linguística é tratada, em média, em um capítulo de cada unidade, capítulo este separado daquele dedicado à produção de textos. Dessa maneira, a reescrita ou avaliação não se configura como espaço que propicia a análise linguística nesse novo tema que lhe dá esse material didático, em diálogo com o discurso das Ciências da Linguagem.

Em relação à presença do professor como mediador do processo de escrita (aspecto destacado como fundamental no processo de escrita, conforme os estudos científicos citados na seção anterior), é preciso fazer algumas considerações.

No Manual do professor do volume 2, as autoras afirmam o seguinte:

(2) Em resumo, seja na reescrita, seja na retextualização (nos termos de Marcuschi), a mediação do professor é crucial. Tornar-se leitor do próprio texto não é uma transição automática, ao contrário, é um exercício que os alunos precisam aprender a fazer. (ALVES; MARTIN, 2016).

Mas, apesar desse discurso direcionado ao professor, de forma geral, nessa coleção didática, esse efeito de "falta de presença do professor" se mantém nas seções de produção textual intituladas "Roteiro de avaliação", em que o lugar do professor no processo de avaliação do texto (lugar construído na memória do discurso escolar) é substituído seja pelas autoras da coleção, que orientam, passo a passo, a avaliação do texto produzido, seja pelos próprios alunos, em processo de autocorreção de seu texto, seja pelos colegas, em algumas produções propostas pelo material.

A seguir, reproduzimos um roteiro de avaliação de uma produção escrita de artigo de opinião, que serve como exemplo do que se encontra na coleção em pauta:

Roteiro de avaliação

Depois de escrever a primeira versão de seu artigo de opinião, é hora de avaliar sua produção com base em alguns critérios para verificar se você conseguiu expressar-se adequadamente nesse gênero. As questões a seguir servem de roteiro para sua avaliação. 
1. O tema a ser desenvolvido fica explícito na introdução?

2. O ponto de vista assumido é evidenciado ao longo do texto?

3. O texto cumpre sua função de convencer o leitor de que seu ponto de vista é válido e deve ser considerado numa discussão sobre esse tema?

4. Os argumentos utilizados foram convincentes/suficientes para persuadir o leitor do ponto de vista defendido?

5. Verifique se a estrutura do texto foi bem trabalhada [...].

6. Verifique também se o uso da linguagem está adequado [...].

7. Por fim, verifique se o título proposto para o texto condiz com o ponto de vista e a argumentação desenvolvida. (ALVES; MARTIN, 2016, p. 151).

O roteiro orienta o escrevente a fazer a autocorreção da primeira versão de seu artigo de opinião, dando ênfase para os aspectos composicionais e estilísticos do gênero em estudo (questões 1, 5, 6 e 7). As questões 2, 3 e 4 estão centradas no desenvolvimento da argumentação, na manutenção de um ponto de vista e na interação com o possível destinatário do texto; no entanto, as autoras falham no quesito de contextualização do texto, visto que não chamam atenção do escrevente para a situação em que o texto será lido, que interfere diretamente na qualidade da argumentação.

Contudo, destacamos aqui que esse roteiro peca não somente pela descontextualização e pouca atenção à constituição social do gênero artigo de opinião, mas também, e principalmente, por não criar um espaço para que o professor participe do processo de revisão/avaliação textual - não há orientações direcionadas ao professor em relação às interferências que possa vir a fazer para intermediar o processo de aprendizagem da atividade escrita em pauta. No Manual do Professor, as autoras orientam o professor para o trabalho com o desenvolvimento de um ponto de vista quando da redação do gênero artigo de opinião, de forma a que o estudante venha a participar em espaços sociais mais amplos defendendo seu ponto de vista. Tem-se, portanto, instrução para lidar com o gênero como espaço da construção de um ponto de vista, mas a presença do professor quando do planejamento e revisão é nula.

Nesse sentido, podemos dizer que a revisão/reescrita, nessa coleção, também ganha um novo tema no diálogo com o discurso científico: está sob a égide de um ensino de escrita cujo objeto são os gêneros. A reescrita, nesse novo contexto, tem como centralidade os aspectos temáticos, composicionais e estilísticos, e não a arquitetônica do gênero. Está restrita à textualidade escolarizada, pouco marcada pela interação efetiva e significativa com o outro-leitor; e não tem, destacamos aqui, como participante ativo o professor, sujeito que aparece pouco na coleção. 


\section{Considerações finais}

Enfım, apesar dos aspectos positivos para a produção textual que as atividades de refacção e/ou reescrita e/ou revisão podem trazer na coleção didática Veredas da Palavra, é preciso atentar para o apagamento da atuação do professor nesse processo, seja como leitor do texto do aluno, seja como mediador da revisão, seja como avaliador.

Assim, aqueles que orientam o processo de avaliação são as autoras do livro, que assumem competência suficiente para eleger critérios para essa avaliação e que se dirigem aos alunos. Estes, por seu turno, farão a revisão de seus trabalhos escritos e, em algumas situações, trocarão seus textos com colegas, que farão também uma leiturarevisão do texto. Praticamente não resta espaço, nesta coleção, para a presença do professor nessa escrita em processo (planejamento, redação, revisão pessoal, revisão feita pelo outro). O professor não ocupa esse espaço significativo de um outro do aluno.

\section{REFERÊNCIAS}

ABAURRE, M. B.; FIAD, R. S.; MAYRINK-SABINSON, M. L. T. Cenas de Aquisição da Escrita: o sujeito e o trabalho com o texto. Campinas: Mercado de letras, 1997.

ALVES, R. H.; MARTIN, V. L. Veredas da Palavra. Manual do Professor. v. 1. São Paulo: Ática, 2016.

BAKHTIN, M. Estética da criação verbal. Tradução Maria Ermantina Galvão. 3. ed. São Paulo: Martins Fontes, 2000.

BRASIL. Secretaria de Educação Fundamental. Parâmetros Curriculares Nacionais: primeiro e segundo ciclos do ensino fundamental. Língua portuguesa. Brasília: Secretaria de Educação Fundamental, 1997.

BRASIL. PNLD 2018: língua portuguesa - guia de livros didáticos - Ensino Médio/ Ministério da Educação - Secretaria de Educação Básica - SEB - Fundo Nacional de Desenvolvimento da Educação. Brasília, DF: Ministério da Educação, Secretaria de Educação Básica, 2017.

FIAD, R. S.; MAYRINK-SABINSON, M. L. T. A escrita como trabalho. In: MARTINS, M. H. (org.). Questões de linguagem. São Paulo: Contexto, 1991.

GERALDI, J. W. A escrita como trabalho: operações e meta-operações de construção de textos. Estudos Linguísticos XXIII, Anais de Seminários do Grupo de Estudos Linguísticos do Estado de São Paulo (GEL), São Paulo, v. 1, 1994. 
GERALDI, J. W. (org.). O texto na sala de aula: leitura \& produção. 2. ed. Cascavel: Assoeste, 1984.

GERALDI, J. W. Heterocientificidade nos estudos linguísticos. In: GEGE (Grupo de Estudos dos Gêneros do Discurso) (org.). Palavras e contrapalavras: enfrentando questões da metodologia bakhtiniana. São Carlos: Pedro e João Editores, 2012.

GINZBURG, C. Sinais: raízes de um paradigma indiciário. In: GINZBURG, C. Mitos, emblemas, sinais: morfologia e história. Tradução Federico Carotti. São Paulo: Companhia das Letras, 1999. p. 143-180.

GRILLO, S. V. de C. Escrever se aprende escrevendo. Sínteses. Teses. UNICAMP/IEL, v. 1, 1996.

GRILLO, S. V. de C. Esfera e campo. In: BRAIT, B. (org.). Bakhtin: outros conceitos-chave. São Paulo: Contexto, 2006.

GRILLO, S.; GLUSHKOVA, M. A divulgação científica no Brasil e na Rússia: um ensaio de análise comparativa de discursos. Bakhtiniana. Revista de Estudos do Discurso, São Paulo, v. 11, n. 2, p. 69-92, maio/ago. 2016. Disponível em: http://revistas.pucsp.br/bakhtiniana/ article/view/23556/19236. Acesso em: 10 jan. 2019.

JESUS, C. A. de. Reescrita: para além da higienização. Sínteses. Teses. UNICAMP/IEL, V. 1, 1996.

MENDONÇA, M. C. A produção textual na esfera escolar: considerações sobre a "escrita como trabalho". Diálogo das Letras, Pau dos Ferros, v. 8, n. 1, p. 3-15, 2019.

MENDONÇA, M. C. Práticas de escrita: diálogos entre ciências da linguagem e ensino/ aprendizagem de língua. Estudos Linguísticos, São Paulo, v. 47, n. 3, p. 758-768, 2018.

MENDONÇA, M. C. O discurso sobre autoria na esfera didático-pedagógica: algumas considerações. Revista da ABRALIN, v. 15, p. 265-284, 2016.

MENDONÇA, M. C. Práticas de escrita e subjetividade. Letras \& Letras (Online), v. 31, p. 43-55, 2015.

MENDONÇA, M. C. O discurso sobre a produção textual de gêneros literários. Letras \& Letras (on-line), Uberlândia, v. 29, n.2, p. 1-15, 2013, 2013. 
POSSENTI, S. Discurso, estilo e subjetividade. São Paulo: Martins Fontes, 1993.

RUIZ, E. M. S. D. Como se corrige redação na escola. Sínteses. Teses. UNICAMP/IEL, v. 4, 1999.

VOLÓCHINOV. V. N. Marxismo e filosofia da linguagem. Problemas fundamentais do método sociológico na ciência da linguagem. Tradução, ensaio introdutório, glossário e notas de S. V. C. Grillo e E. V. Américo. v. 1. São Paulo: Editora 34, 2017. 